\title{
EDITORIAL
}

\section{Imaging of airway cells}

\author{
E. Puchelle, J. Zahm, N. Bonnet
}

Airway cells, as with many other living cells, are dynamic and occupy a three-dimensional (3-D) space. During the processes of proliferation, differentiation and migration, ciliated cells, secretory cells and all the airway cells undergo a rearrangement of their cytoskeleton as they progress through the cell cycle or undergo differentiation or dedifferentiation. During migration, the airway cells pass through coordinated shape changes and spread over the extracellular matrix. Light microscopy associated with new culture techniques plays a crucial role in airway cell biology research. Although the airway cells have a dynamic 3-D organization, our understanding is still most exclusively based on two-dimensional (2-D) static imaging after fixation of the cells, therefore analytical conditions are very different from reality [1].

We propose in this editorial to focus on two main recent approaches allowing study of the 3-D microscopic appearance and dynamic behaviour of airway cells.

Classically, cell biologists analyse a phenomenon or localize a subcellular structure by fixing a sample of either human airway tissue or cells in culture, and after embedding the sample in a matrix, cutting sections for observation with a microscope. This is, for example, the case for detecting a given antigen inside the whole volume of the cell. In most studies, an antibody raised against the antigen and bound to a fluorescent probe (fluorochrome) is observed under optical immunofluorescence microscopy. The limitation of this technique is due to the difficulty of obtaining precise information on the localization of the antigen throughout the whole cell. The most widely used optical sectioning technique is the differential interference contrast (Nomarski) imaging. This permits the visualization of a flat unstained specimen, with the addition of a 3-D "shadowcast" appearance [2]. This method provides good optical sectioning capabilities near the surface of a specimen, although light scattering can degrade images from deep sections. The major restriction of Nomarski imaging is that while it gives good visualization of cellular organelles, it lacks the specificity needed for molecular identification [2]. Confocal laser scanning microscopy, combined with image processing techniques has allowed, for about a decade, the appropriate presentation and observation of immunofluorescent dyes within a 3-D cell structure. The advantage of the confocal method is that light emitted or scattered from planes other than the focus plane will not be detected and the detected signal will be characteristic of only a single plane within the specimen. This

Unité INSERM 314, IFR 53, Hôpital Maison Blanche, Reims Cédex, France.

Correspondence: E. Puchelle, Unité INSERM 314, IFR 53, Hôpital Maison Blanche, 45, rue Cognacq Jay, 51092 Reims Cédex, France. Fax: 33326065861. explains why the confocal microscope is said to be able to make optical sections. This technique allows the observation of two antigens on XZ or XY optical sections collected at $0.5 \mu \mathrm{m}$ intervals, either parallel or perpendicular to the apical/basolateral axis of the airway cells. Such a technique has been applied to the differential localization of the cystic fibrosis transmembrane conductance regulator (CFTR) in normal and cystic fibrosis (CF) airway epithelium [3]. In normal epithelium, labelling was restricted to the surface apical compartment of the ciliated cells. In contrast, in the CF airway epithelium (homozygous for the AF508/508 mutation), CFTR markedly accumulated in the cytosol of all the epithelial cells.

Of particular interest is the recent study of STROHMAER et al. [4] who used the nondestructive procedures of confocal laser scanning microscopy, in combination with computer-assisted methods, to visualize human lung cancer cells in the process of penetrating collagen gels. By using a fluorescent dye (DiOC63) for cell surface contrast staining and an antibody against cathepsin, they could clearly visualize the spatial relationship between cathepsin cell organelles and tumour cell motility in a 3-D model of extracellular matrix. This study exemplifies the use of appropriate fluorescent dyes and specific antibodies on association with computer analysis and vizualization of volume data for the study of spatial relationships between molecular structures and their dynamic properties and functions.

More recently, video-rate (or faster) confocal scanning light microscopy [5] has been developed to investigate both fixed and/or live cells. This approach is of particular interest in visualizing real-time intracellular organelle motion or motility of the cell periphery using fluorescent probes [6] available for studies with living cells (table 1).

Most of the airway cellular processes are dynamic [7]. The ability of cells to move is crucial for airway maturation during embryogenesis as well as for epithelial wound repair, which requires spreading and migration of airway epithelial cells. Other cellular processes involve motility of organelles such as cilia which are required for mucociliary transport. The evaluation of ciliary dysfunction has been generally performed using electron microscopy. Alternative videomicroscopic techniques have been recently developed to study the functional activity of cilia. KORNGREEN and PRIEL [8] have developed a unique system to measure simultaneously the intracellular calcium concentration $\left(\left[\mathrm{Ca}^{2+}\right]_{\mathrm{i}}\right)$ and the ciliary beat frequency thus providing a tool for observing physiological cause and effect in the ciliary cell. These dynamic microscopic methods are particularly useful to determine precisely the functional ciliary defect in primary ciliary dyskinesia syndrome [9]. The endocytosis and phagocytosis processes in airway epithelial and inflammatory cells and the exocytosis process in 
Table 1. - Examples of fluorescent probes available for studies with living cells

\begin{tabular}{|c|c|}
\hline & Fluorescent probe \\
\hline $\mathrm{Ca}^{2+}, \mathrm{Na}^{+}, \mathrm{K}^{+}$ & Quin-2, Fura-2, Indo-1, Indo-2, \\
\hline $\mathrm{Mg}^{2+}, \mathrm{Cl}^{-}, \mathrm{Zn}^{2+}$ & Fluo-3, SPQ \\
\hline Thiol groups & $\begin{array}{l}\text { Bimanes, 5-chloromethyl-fluores- } \\
\text { ceinediacetate }\end{array}$ \\
\hline Membrane potentials & $\begin{array}{l}\text { Rhodamine 1, 2, 3-tetramethylrhod- } \\
\text { amine }\end{array}$ \\
\hline Lipid peroxidation & $\begin{array}{l}\text { Dihydrofluoresceines and } \\
\text { dihydrorhodamines }\end{array}$ \\
\hline Viability & Propidium iodide, calceine \\
\hline \multicolumn{2}{|l|}{$\begin{array}{l}\text { Localization of } \\
\text { organelles }\end{array}$} \\
\hline Acidic organelles & Neutral red \\
\hline Endoplasmic reticulum & Carbocyanines \\
\hline Golgi & Ceramides \\
\hline Mitochondria & Rhodamines \\
\hline Nucleus & $\begin{array}{l}\text { Acridines, propidium iodide, } \\
\text { Hoechst }\end{array}$ \\
\hline Membranes & Fluorescent phospholipids \\
\hline
\end{tabular}

secretory cells are other examples requiring the analysis of 3-D structures which change rapidly over time. The in situ visualization of the secretory process in respiratory type epithelium [10] and in bronchial submucosal glands [11] after acetylcholine stimulation has been analysed by sequential videomicroscopy. Both studies demonstrated that part of the mucus is secreted in particulate form suggesting that mucus may be released from the airway surface epithelium or submucosal glands by an apocrine mechanism. Videomicroscopy is also particularly useful for the analysis of molecular dynamics in cells [12].

Human airway gland cells may respond differently to various agonists known to stimulate the release of airway mucus. The regulation of exocytosis mainly depends on the secretory cell type and on the oscillation of $\left[\mathrm{Ca}^{2+}\right]_{j}$.

A method has been developed recently, combining the use of a $\mathrm{Ca}^{2+}$ fluorescent probe (Indo-1) and quantitative ultraviolet laser microspectrofluoremetry to analyse the dynamic changes in $\left[\mathrm{Ca}^{2+}\right]_{\mathrm{i}}$ in human tracheal submucosal serous gland (HTG) cells at the single-cell level in response to externally applied secretagogues $[13,14]$. Using a combination of this method and the videomicroscopic monitoring of quinacrine fluorescence, (which allows the labelling of secretory granule exocytosis), they have shown that dynamic changes in $\left[\mathrm{Ca}^{2+}\right]_{\mathrm{i}}$ in HTG cells are directly implicated in the initiation of the exocytotic process of the secretory granules and more specifically that human neutrophil elastase may play a major role in the exocytotic process of mucus release during human airway inflammation. This example clearly demonstrates that microscopy can be viewed as a dynamic instrument allowing the study of the biological activity of living cells in real-time in a wide range of cellular processes such as airway mucus exocytosis and migration of airway cells such as that recently described during airway epithelial wound repair.

The respiratory epithelium is frequently injured by inhaled toxic agents, micro-organisms, allergens and oxidant pollutants, leading to an alteration of the epithelium barrier integrity. Whatever the source of injury, the response of the respiratory surface epithelium to such injuries is characterized by a succession of cellular events varying from the loss of surface epithelial junctional in- tegrity to the partial or complete denudation of the epithelium. A similar situation has been described in asthma, as well as in infectious diseases such as chronic bronchitis, bronchiectasis and cystic fibrosis [15]. The mechanisms allowing airway epithelium repair involve spreading, migration and proliferation of airway cells. Using an in vitro wound repair model of respiratory epithelial cells, ZAHM et al. [16] developed a videomicroscopic technique allowing the analysis in real-time of the migration kinetics of either individual cells or a cell population during the wound repair process. The cell tracking was carried out by incubating wounded cell cultures with a fluorescent dye (Hoechst 33258) which fluorescently stains the nucleus of living cells. The wounded culture was placed on the stage of an inverted microscope enclosed in a minitransparent culture chamber. The images from the video-sequence were digitized and the use of specific software allowed the detection of the cell nucleus and the analysis of the nucleus trajectories. The software was able to track a cell population of about 100 cells, allowing the calculation of a mean migration speed. The temporal analysis of the respiratory cell migration speed showed that the cell population at the wound edge remained fairly constant $\left(\sim 40 \mu \mathrm{m} \cdot \mathrm{h}^{-1}\right)$ during the first three days of repair and decreased progressively up to wound closure. This quantitative cell tracking approach is currently being extended to 3 -D cultures.

A series of videophase-contrast images, taken at $3 \mathrm{~min}$ intervals during the wound repair, allowed the visualization of the lamellipodia dynamics of the cells located at the wound edge. Cell spreading was characterized by the continuously changing shape of the lamellipodia with a constant polarity, leading the unidirectional cell movement. During the wound repair, cell surface adhesion molecules, in particular integrins such as $\alpha 5 \beta 1$ integrins and their fibronectin ligand appear to play a major role in cell migration. In addition to the analysis of the expression of molecules involved in airway cell migration [17], the videomicroscopic analysis of cell motility allows researchers to identify the chronology of the dynamic events in epithelial wound repair.

Apart from tracking moving cells, fluorescence videomicroscopy may be very useful for analysing the biological activity of living cells in real time. BonNET and ZALIM [18] have recently described a local modelling approach and multivariate statistical analysis to provide a global approach for studying the temporal behaviour of cells. They applied these techniques to the analysis of basal and stimulated chloride secretion by airway cells, which is particularly useful for evaluating the functional expression of the CTFR protein which may be abnormal in CF airways.

Today, the microscope can be viewed as a dynamic instrument which makes possible the simultaneous determination of biochemical and functional properties in individual or populations of living cells. The availability of optical probes for biological activity in association with powerful image acquisition and analysis technology should be more widely applied in the dynamic imaging and study of living airway cells.

\section{References}

1. Thomas C, Devries P, Hardin J, White J. Four-dimensional imaging: computer visualization of 3D movements in living specimens. Science 1996; 273: 603-607. 
2. Brocksch D. Phase-contrast Nomarski (differential interference) contrast, and dark-field microscopy: black and white and color photomicrography. In: JE Celis ed. Cell Biology Laboratory Handbook. vol 2 Part 4. Academic Press, 1994; pp. 5-14.

3. Puchelle E, Gaillard D, Ploton D, et al. Differential localization of the cystic fibrosis transmembrane conductance regulator in normal and cystic fibrosis airway epithelium. Am J Respir Cell Mol Biol 1992; 7: 485-491.

4. Strohmaier AR, Porwol T, Acker H, Spiess E. Tomography of cells by confocal laser scanning microscopy and computer-assisted three dimensional image reconstruction: localization of cathepsin B in tumor cells penetrating collagen gels in vitro. J Histochem Cytochem 1997; 45: 975-983.

5. Boyde A, Gray C, Jones S. Real time confocal microscopy and cell biology. In: JE Celis, ed. Cell Biology Laboratory Handbook. vol 2 Part 4. Academic Press, 1994: pp. 96-101.

6. Nagelkerke JF, de Bont HJGM. Use of videomicroscopy to study the mechanisms of cytotoxicity in vitro in individual living cells. Toxicol in vitro 1997; 11: 531-534.

7. Sanger M, Sanger M. Analysis of cell motility in living cells. In: Jockusch JM, Mandelkow E, Weber K, eds. The Cytoskeleton. Berlin Heidelberg, Springer-Verlag. 1995; pp.127-134.

8. Korngree A, Priel Z. Simultaneous measurement of ciliary beating and intracellular calcium. Biophys $J$ 1994; 67: 377-380.

9. Bonnet P, Nunge H, Zahm. JM, Gagnaire F. Ex vivo technique for evaluating the effect of chemical vapours on mucociliary activity. J Appl Tox 1994; 14: 369-374.

10. Puchelle E, Beorchia A, Ménager M, Zahm JM, Ploton D. Three-dimensional imaging of the mucus secretory process in the cryofixed frog respiratory epithelium. Biol Cell 1991; 72: 159-166.

11. Inglis SK, Corboz M, Taylor AE, Ballard ST. In situ visualization of bronchial submucosal glands and their secretory response to acetylcholine. Am J Physiol 1997; 272: L203-L210.

12. Ozawa K, Tamura A, Ikeda K, et al. Videomicroscopy for analysis of molecular dynamics in cells. J Pharm Biomed Anal 1997; 15: 1483-1488.

13. Maizières M, Kaplan H, Millot JM, et al. Neutrophil elastase promotes rapid exocytosis in human airway gland cells by producing cytosolic $\mathrm{Ca}^{2+}$ oscillations. Am $J$ Respir Cell Mol Biol 1998; 18: 32-42.

14. Millot JM, Pingret L, Angiboust F, Bonhomme A, Pinon JM, Manfait M. Quantitative determination of free calcium in subcellular compartments as probed by Indo-1 and confocal microspectrofluorometry. Cell Calcium 1995; 17: 354-366.

15. Puchelle E, Zahm JM. Repair processes of the airway epithelium. In: Chretien J, Dusser D, eds. Environmental Impact on the Airways: From Injury and Repair. M. Dekker Inc. Series Lung Biology in Health and Disease 1996; pp.157-182

16. Zahm JM, Kaplan H, Hérard AL, et al. Cell migration and proliferation during the in vitro wound repair of respiratory epithelium. Cell Motil Cytoskeleton 1997; 34: 33-43.

17. Hérard AL, Pierrot D, Hinnrasky J, et al. Fibronectin and its $\alpha 5 \beta 1$ integrin receptor are involved in the wound repair process of the airway epithelium. Am J Physiol 1996: 271: L726-733.

18. Bonnet N, Zahm JM. Analysis of image sequences in fluorescence videomicroscopy of stationary objects. Cytometry 1998; 31: 217-228. 